\title{
Gestal'terapia: metodológica da atualização performática improvisativa da performação figura e fundo, performática da forma, performática da ação, do contato, performática da atualização
}

\section{Gestal'therapy: methodologic of actualization improvisative performatic of the performaction figure-ground, performatic of form, performatic of action, of Contact, performatic of actualization}

\author{
Afonso Henrique Lisboa da Fonseca* \\ Coordenador da Escola Experimental de Psicologia e Psicoterapia Fenomenológico \\ Existencial - Maceió, AL, Brasil
}

\begin{abstract}
Resumo
A questão metodológica da Gestal'terapia é a questão da ação, da ação contactante. A ação, como vivência fenomenológico existencial de possilbidades e do desdobramento destas, é per-feita, ou seja, é feita pelo desdobramento vivencial, fenomenológico existencial, destas possibilidades. Isto caracteriza 0 que se entende por performance. No sentido fenomenológico existencial. A performática da ação, da atualização, é o que almejamos na metodológica da dialógica inter-humana da relação cliente/grupo-terapeuta/facilitador em Gestal'terapia.
\end{abstract}

Palavras-chave: Ação, Atualização, Forma, Formação, Figura e fundo, Gestalt, Gestal'terapia, Performance.

\begin{abstract}
Gestal'therapy methodological issue is the issue of action, contacting action. Action as phenomenological existential living and living of the unfolding of possibilities is per-fect, is done through the living unfolding of this possibilities. This means what is performance, in the phenomenological existential sense. Performatic of action, of actualization, it is what we aim as the inter human dialogic of the relation client/group-therapist/facilitator in Gestal'therapy.
\end{abstract}

Keywords: Action, Actualization, Form, Formation, Figure and ground, Gestalt, Gestal'therapy, Performance.

O logos metódico da Gestalt Terapia é o da criação de condições inter- humanas, por parte do gestalt terapeuta, na relação com o cliente, para a potencialização do retorno, e para o desenvolvimento da habitualidade do retorno, por parte do cliente, ao modo de sermos 
da ação, da atualização de possibilidades. Criação de condições, por parte do terapeuta, para a potencialização do retorno do cliente ao improvisativo modo per-form-ático da ação, da potência, e da ação, do contato, da atualização, da interpretação fenomenológico existencial.

Ou seja, o logos metódico da Gestalt Terapia se centra na criação de condições para a recuperação, e para o desenvolvimento da habitualidade, na vida do cliente, da alternância, natural e organísmica, entre (1), de um lado, os modos de sermos da não ação, do não contato; modos de sermos não atualizantes (como o modo reflexivo e o modo comportamental de sermos da não ação e do não contato); e (2) do outro lado, o nosso modo ativo de sermos, nosso atualizante, modo contactante, que é, essencialmente, fenomenológica e existencialmente form-ativo; no sentido do processo psicológico compreensivo (nunca explicativo), vivencial, da formação compreensiva de figura e fundo. Modo de sermos eminente e especificamente performativo, performático, e atualizante.

Para entendermos o logos metódico da Gestalt-terapia, necessitamos, pois, de uma clareza da concepção de Contato. Em especial de Contato como característica da Ação. E necessitamos de uma clareza da concepção de Ação, como desdobramento e atualização experimentais de possibilidades. Inerentes, estas possibilidades, à vivência do modo fenomenológico existencial de sermos. Necessitamos de uma clareza de compreensão deste nosso processo da Ação e do Contato, como processo de formação de figura e fundo. Como um processo fenomenológico existencial, eminentemente ativo; em que a forma emerge, e se forma, a partir da vivência de possibilidades características, que impregnam a vivência, de nosso modo fenomenológico existencial de sermos.

E, para entendermos o logos metódico da Gestalt Terapia, precisamos entender a performance como o próprio processo performativo fenomenológico existencial de atualização de possibilidades. Um processamento sempre, eminentemente e especificamente ativo, e compreensivamente vivido; eventualmente motor. Através do qual, a partir da vivência de suas potências, as possibilidades, vividas fenomenológico existencialmente, transitam de um estado de précompreensão, para se constituir compreensivamente.

(a) Meramente como compreensão. Ou seja, de modo meramente compreensivo de sermos; ou

(b) na ação compreensivamente motora, ação inextrincavelmente compreensiva e motora; ambas especificamente fenomenológicas e existenciais, naturalmente.

O Contato é característica de precisão qualitativa e expressiva da Ação. 
É a qualidade da ação que tangencia efetiva, e otimamente, e se anima, das emergências e desdobramentos vivenciais, fenomenológico existenciais, das potências da possibilidade vivida. E que, ação, efetivamente, portanto, toca, inovativa e potentemente (encantadoramente), a dimensão do mundo, das coisas, da vida: dos modos de ser, acontecidos, coisi-ficados. Quer dizer, o contato é característica da ação, que transita da potência do possível à dimensão das coisas, da vida, e modos de ser acontecidos de um modo esteticamente inovativo, engendrando e criando o novo, a novidade.

O Contato caracteriza-se, assim, na vivência fenomenológica, estésica, estética, como o tangenciamento compreensivo ótimo da possibilidade e de seu desdobramento. Tangenciamento que permite e potencializa a sua ótima expressão estética na ação.

Eminente e especificamente compreensiva, a Ação se dá, desta forma, como a atualização de possibilidades especificamente compreensiva que se constitui originariamente, e estéticamente, como processo de formação de figura e fundo fenomenológica e existencialmente vivido. Constitui-se, desta forma a ação, como o processo fenomenológico existencial de atualização, de desdobramento, da potência de possibilidades.

No modo fenomenológico existencial de sermos, a possibilidade nos é dada, anteriormente à sua plena apreensão compreensiva, como précompreensão.

A partir desta condição de pré-compreensão, a partir de sua própria força, de sua própria potência como possi-bilidade, a possibilidade fenomenológico existencialmente vivida, fenomenologicamente, vivencialmente, se desdobra, se atualiza -- sempre de modos précompreensivos, e progressivamente compreensivos, vivenciais, fenomenológicos, existenciais. Desdobra-se vivencialmente, assim, a possibilidade vivida, em ação, atualização, mais ou menos contactantes.

Ação, Cont-ato. Que podem se dar, assim, como observamos, como ação e como contato,

(1) meramente ao nível da compreensão, minimamente motores: meramente compreensivos, assim; ou

(2) que podem se dar, se desdobrar, ao nível da ação, atualização, contato, compreensivos e motores.

\section{Performance}

Todo este per-curso vivencial, fenomenológico, e existencial, "subjetivamente" vivido, da atualização - atualização meramente compreensiva, ou compreensiva e motora -, todo este processo da ação, e do contato, é o que podemos chamar de Performance. Per- 
cursar vivido, mais, ou menos, vívido vivido, fenomenológico existencial; psicológico, nesse sentido.

É, assim, um per-curso vivenciado - a performance -, que parte da vivência da pré-compreensão da possibilidade - da vivência da pré-compreensão da pré-forma, e pré-formação compreensivas da possibilidade; da pré-formação da forma, da pré-compreensão -, e direciona-se no sentido da compreensão, da vivência compreensiva, da ação. Do desdobramento compreensivo da possibilidade. Que pode ser dar de um modo meramente compreensivo, ou de um modo compreensivo e motor.

Todo o processo - todo ele, pré-compreensivo, e sequencialmente compreensivo, e eventualmente motor -, é o que podemos entender como, e chamar, de performance.

Performance aí entendida, naturalmente, específica e inteiramente, como, e do ponto de vista, da vivência fenomenológico existencial "subjetiva". E, naturalmente, entendida, aí, sem nenhuma conotação quantitativa, ou de eficiência. Mas especificamente do ponto de vista fenomenológico existencial qualitativo, poiético.

De modo que a ação, a atualização, o contato, são especificamente performáticos, neste sentido vivencial; própria e especificamente fenomenológico existencial. Sentido, vivencial, no qual a forma ativa, a atividade da formação, se constituem, em emergência compreensiva, a partir de um fundo pré-compreensivo. Neste sentido, a performancepode ter qualidades de uma performance meramente fenomenológico existencial compreensiva, ou pode ter qualidades de uma performance que, simultânea e sinergicamente, é fenomenológica e existencial, compreensiva e motora... Sempre improvisativa. (FONSECA, 2005)

Eminente e especificamente performáticos e improvisativos, neste sentido, a atualização, a ação, o contato -, a vivência metodológica da Gestalt Terapia é, portanto, específica e eminentemente, performática, per-form-ativa, im-pro-vis-ativa.

$\mathrm{Na}$ medida em que o que interessa do cliente é a performance da atualização das possibilidades que the são emergentes, ativas, presentes e atuais na pontualidade dos momentos de sua atualidade existencial: a ação, o contato, como performance do desdobramento, da atualização compreensiva, ou compreensiva e motora, das possibilidades que Ihe são emergentes.

Daí que se constitui a metodologia da Gestalt-Terapia como uma Teatralização performática das possibilidades emergentes como atualidade e atualização fenomenológico existenciais do cliente.

Num momento, e para um, é a dor de uma perda especifica, para outro é a configuração da insatisfação, para outro é a saudade, para outro é a tristeza, para outro é o desespero desvairado, para outro é 
o desespero manso, para outro é a dúvida, a incerteza, a vivência de finitude, a vivência do sem saída...

\section{Condições metodológicas em Gestalt-terapia para a potencialização da performance da atualização, da ação, do contato}

Performática, fenomenológico existencial, por definição --, a partir das pulsões e prepotências de suas próprias possibilidades atuais -, a vivência do cliente da Gestalt Terapia tem como potencializadoras a disposição per-form-ativa, a performance relacional, dialógica, e igualmente vivida e fenomenológico existencial, de um gestaltterapeuta fenomenológico-existencial e, igualmente, performático.

Para tal, e como tal, desta forma, em seu desempenho metodológico, na dialógica inter humana de sua relação com o cliente, o gestaltterapeuta privilegia o modo de sermos eminente e especificamente empírico, experimental, e poiético - num sentido fenomenológico existencial. Processo que se dá e desdobra de um modo eminente e especificamente improvisativo, na pontualidade dialógica do encontro inter humano com o cliente.

Assim, o gestalt-terapeuta privilegia a sua relação inter humana (BUBER, 1982) com o cliente, a partir de uma disposição fenomenológico existencial empírica e experimental. Disposição que privilegia, portanto, a prêt-potência e desdobramento, préteórico, pré-reflexivo, do possível, fenomenológico existencialmente presentes, tanto como vivência sua, como enquanto a vivência do cliente. E como dialógica entre ambos.

Só assim o terapeuta pode sugerir ao cliente que privilegie, no âmbito de seu trabalho psicológico, a vivência de seu modo fenomenológico-existencial de ser. De modo que ele permita e privilegie a vivência da emergência, e do desdobramento, das possibilidades ativas em sua atualidade, e a atualização, fenomenológico existencial; os seus processos de atualização, meramente compreensivos, ou compreensivos e motores, e os seus processos de superação.

Só assim ele pode sugerir ao cliente uma disposição que é fenomenológico-existencial empírica, experimental, e poiética, com relação às possibilidades presentes na vivência fenomenológica de sua atualidade existencial. Só assim o terapeuta pode acompanhar e interagir de um modo interativa e inter-humanamente dialógico, empírico, experimental, provocativo, e poético, com o cliente.

De modo que podemos entender que - da mesma forma que se preconiza a vivência de um modo fenomenológico-existencial performático da ação e do contato para o cliente, na dialógica de sua inter humana inter ação com o terapeuta, em Gestalt Terapia -, 
preconiza-seuma idêntica disposição para o gestalt-terapeuta, na vivência do logos metódico da abordagem.

É importante entender que esta disposição é empírica e experimental, num sentido especificamente fenomenológico existencial, além do que poiética, e inter humanamente dialógica. E é importante entender, naturalmente, o que isto significa.

Como observamos, a Atualização - dimensão humana fundamental para a concepção e método das abordagens fenomenológico existenciais de psicologia e psicoterapia, notadamente a GestaltTerapia e a Abordagem Rogeriana -,a atualização se refere à ação propriamente dita. Ou seja, ao ato, que é, especificamente, como observamos, a vivência fenomenológico existencial de possibilidades, e do seu desdobramento performáticos.

Atualidade se refere, portanto, a aquilo que é ato, atual. Ação, atualização. Atualidade é a qualidade daquilo que é ato. Ou seja, a vivência que é vivência de possibilidade, e vivência do desdobramento de possibilidade, fenomenológico existencialmente vividas.

De modo que, quando falamos de atualidade, não nos referimos a um recorte de tempo cronométrico - que é a dimensão do tempo coisificado, mecânico, calculativo... Com atualidade, referimo-nos à própria vivência fenomenológico existencial da temporalidade própria e especificamente inerente à ação. Ou seja, inerente e específica à atualização. A temporalidade vivencial, fenomenológico-existencial, inerente e específica, que a atualização da possibilidade em questão, sua vivência e desdobramento, instauram e determinam.

Da mesma forma, quando falamos de Presente, também não nos referimos a um recorte de tempo cronométrico. Mas, especificamente, a este modo de sermos que instala e desdobra uma temporalidade própria e específica, singular e intransferível. A temporalidade da vivência da possibilidade e da vivência de seu desdobramento. Vivências que se dão especificamente como ação. Que são ato-ais, atuais, portanto. O presente, na verdade, é um modo de sermos. Um modo característico da vivência da ação. Atual, portanto.

O termo Pres-ente se refere ao modo 'não coisa' de sermos - referese, especificamente, ao modo fenomenológico e existencial, dialógico, de sermos. Impregnado este da vivência pré-compreensiva, e compreensiva, de possibilidades, e de seus desdobramentos em ação, atualização...

O Presente se refere, portanto, ao nosso modo atu-al de sermos, a nossa atu-alidade à ação, que é especificamente fenomenológico existencial, e dialógica. O presente, o nosso modo, portanto, de sermos presentes, atuais, não é da ordem da coisidade, não é da ordem da realidade, não é da ordem das relações de causalidade, nem da ordem das relações sujeito objeto, não é da ordem da 
utilidade; e não é, portanto, da ordem do prático, nem da ordem do pragmático.

O presente, a atualidade, é empírico, não teorético, num sentido fenomenológico existencial. Nem é comportamental.

O presente caracteriza-se especificamente, também, como experimental. Que é a aquiescência, e ativa cumplicidade, com a implicação inerente a sua vivência e desdobramento, como desdobramento da atualização de possibilidade vivida, como desdobramento da ação. A afirmação da afirmação, como diria Nietzsche.

\section{Poiético}

No caso da Gestalt Terapia, e das abordagens fenomenológicoexistenciais de psicologia e de psicoterapia, é fundamental a consideração pelo modo poiético de sermos.

Desde Aristóteles, temos a considerar os modos teórico, prático e poiético de sermos.

O modo poiético de sermos diz respeito ao modo de sermos da produção criativa. A partir da vivência fenomenal de possibilidades, e de seus desdobramentos na ação; através do processo da vivência e atualização de possibilidades, através do processo da ação, do contato. Os modos teórico e prático de sermos dizem respeito a um rompimento da imediaticidade, e da implicação fenomenológico existencial, inerentes à vivência do modo poiético de sermos. Préreflexivo, pré-conceitual. vivido, fenomenológico.

Na pontualidade da vivência, potencialmente ativa, de nosso modo fenomenológico-existencial de sermos, estamos, de imediato implicados. Somos cúmplices, de nossas possibilidades e de nossos devires, de nossas possibilidades e possibiltações. De nossas possibilidades e atualizações.

Não 'temos' possibilidades e devires: somos possibilidades e devires. Ontologicamente, fenomenológico existencialmente, somos cúmplices, 'cumplicados', implicados, em nossas possibilidades e devires. Podemos nos negar, mas, ontologicamente, somos e devimos assim. Daí que a existência, como observou Nietzsche (1978, p.112), "pode se dizer ser aquilo que se auto supera indefinidamente". Condição que não nos ocorre em nossos modos teorético, e prático de sermos.

O modo teórico de sermos - reflexivo, conceitual, explicativo - se caracteriza maiormente pela ruptura desta implicação, pela ruptura da imediaticidade desta implicação compreensiva com a possibilidade, que é característica da pontualidade momentânea de nosso modo vivencial, fenomenológico-existencial, dialógico, de sermos. No caso do nosso modo teorético de sermos esta ruptura é ex-plicativa, é a 
ex-plicação; diversa da implicação, cum-plicação, vivenciaiscaracterísticas da vivência fenomenológico existencial de nossas possibilidades e possibilitações, características do modo de sermos de nossa atualidade e de nossa atualização. A explicação pode se constituir como mediação conceitual, re-flexiva, teorizante. Que se origina especificamente do afastamento do vivido, e pela reflexão sobre os resultados poiéticos da atualização vivencial.

Rompida assim a imediaticidade da im-plicação com vivência de possibilidade e com o seu desdobramento na ação, rompidaesta cumplicidade com a potência do possível e com a sua atualização, podese constituir e se dar a ex-plicação, a re-flexão, agora teóricas. Impotentes, podemos dizer. Importantes em seus momentos próprios, mas que não podem substituir a precedência e a importância ontológicas da imediaticidade e implicatividade características da vivência poiética, do vivido fenomenológico existencial, caracteristicamente prenhe de possibilidades e de atualização, de possibilidades de superação.

Freud não explica? Numa abordagem fenomenológico-existencial não se explica nada. Nosso interesse é o que acontece como e ao nível da vivência fenomenológico-existencial, que é da ordem da implicação compreensiva com o possível, com a ação e seus desdobramentos.

O prático, o modo prático de sermos, se caracteriza, também, por uma ruptura com esta implicação, cum-plicação, compreensiva com a possibilidade pontualmente vivida em nosso modo fenomenológico existencial de sermos, com a ação com a atualização. O vivido fenomenológico existencial dialógico, que é vivência de possibilidade e de ação, atualização, dá-se em um modo de sermos que não o modo de ser das relações de causa e efeito, da dicotomização sujeitoobjeto, e está igualmente fora do moído de sermos das relações de utilidade, e da funcionalidade com o acontecido.

A ação, a atualização são poiéticas. Nem teoréticas nem práticas. E se caracterizam pela vivência presencial e implicativa da possibilidade e de seus desdobramentos. Ainda que tenham originalidade e força estética e criativa, ainda que revolucionem o acontecido, não têm o compromisso com a utilidade ou com a funcionalidade, que é característico do prático, ou do pragmático.

Assim, ao contrário, podemos dizer que a ação, a atualização, o processo da atualização de possibilidades, são característica e eminentemente despropositados, gratuitos, disfuncionais, inúteis, mais ou menos inconvenientes, em seus processos produtivos, poiéticos. Ainda que impregnados do gozo da atualização, e das forças estéticas de sua orginalidade. Que implicam sempre a superação das aporias da finitude do acontecido.

Assim, o modo prático de sermos está pautado pela utilidade e pela ação funcional, em relação ao princípio de sobrevivência. Enquanto que o modo poiético de sermos não é da ordem do uso e da utilidade. 
Orienta-se pela superação, e não pela conservação. Da mesma forma que não é da ordem da dicotomização sujeito-objeto, da ordem da causalidade, nem mesmo da ordem da realidade - na medida em que é específica e eminentemente da ordem do possível e da possibilidade; e da atualização - da realização, e não da realidade...

\section{Referências Bibliográficas}

BUBER, M. Elementos do Inter-Humano. In: Do Diálogo e do Dialógico. São Paulo: Perspectiva, 1982. p. 73-141.

FONSECA, A.H.L. Dialógica e arte dramática da improvisação. Vislumbre-e-ato do possível propulsivo. Sobre o sentido e importância do improvisativo na concepção e método da Gestalt-terapia e da Psicologia e Psicoterapia Fenomenológico Existencial. In: Gestalt Terapia Fenomenológico Existencial. Maceió: Pedang, 2005. p. 890.

NIETZSCHE, F. Assim Falou Zaratustra. Mira-Sintra: EuropaAmérica, 1978.

\section{Endereço para correspondência}

Afonso Henrique Lisboa da Fonseca

Rua Conde de Irajá, 65/105, CEP 570000-000, Pajussara, Maceió-AL , Brasil

Endereço eletrônico: ahl.fonseca@gmail.com

Recebido em: 01/02/2009

Aceito para publicação em: 13/04/2009

Editor responsável: Eleonôra Torres Prestrelo

\section{Notas}

* Psicólogo 